\title{
Swallowing dysfunction in patients hospitalised due to a COPD exacerbation
}

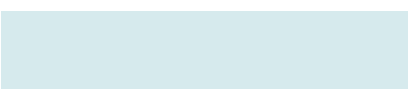

Copyright $\odot$ The authors 2021

This version is distributed under the terms of the Creative Commons Attribution NonCommercial Licence 4.0. For commercial reproduction rights and permissions contact permissions@ersnet.org

Received: 18 Aug 2021 Accepted: 19 Aug 2021$$
\text { ๑ @®@ }
$$

From the authors:

We thank N. Terzi and co-workers for taking an interest in our work and for their valuable comments. Although there are many studies on the coordination of breathing and swallowing, there is still much to investigate and learn about swallowing function in stable and acute COPD. In fact, few published studies have investigated swallowing function in patients hospitalised due to an acute illness other than stroke [1] and this is true for COPD patients with an acute exacerbation [2-4]. There is also much to learn regarding patient-reported outcomes, which was one focus of our study.

We are very pleased to hear that $\mathrm{N}$. Terzi and co-workers research group has performed an interventional study on COPD patients admitted to the intensive care unit for an acute exacerbation of the disease and investigated swallowing function during noninvasive ventilation (NIV) [5]. NIV is often used on patients with hypercapnia in order to assist breathing, and as a result a more optimal breathing process facilitates the swallowing function. The fact that the patients chose to switch off the ventilator during swallowing, and turning it back on immediately after, opens up opportunities for the patients to control the treatment in an optimal way. Hopefully this will be part of the treatment in the future.

Taken together, our study [6] and the results presented by N. Terzi and co-workers show that swallowing dysfunction is common in COPD patients with severe exacerbations, but also that this kind of dysfunction is potentially correctable, at least in some patients. Further intervention studies on this topic are urgently needed.

Margareta Gonzalez Lindh $\oplus^{1,2}$, Christer Janson $\oplus^{3}$ and Hirsch Koyi $\circledast^{2,4}$

${ }^{1}$ Dept of Neuroscience, Uppsala University, Uppsala, Sweden. ${ }^{2}$ Centre for Research and Development, Uppsala University/Region Gävleborg, Uppsala, Sweden. ${ }^{3}$ Dept Medical Sciences, Respiratory, Allergy \& Sleep Research, Uppsala University, Uppsala, Sweden. ${ }^{4}$ Dept of Respiratory Medicine, Karolinska Institute, Stockholm, Sweden.

Corresponding author: Margareta Gonzalez Lindh (margareta.gonzalez.lind@regiongavleborg.se)

Provenance: Invited article, peer reviewed.

Conflict of interest: None declared.

References

1 Spronk PE, Spronk LEJ, Lut J, et al. Prevalence and characterization of dysphagia in hospitalized patients. Neurogastroenterol Motil 2020; 32: e13763.

2 Robinson DJ, Dunne PJ, Greene Z, et al. Oropharyngeal dysphagia in exacerbations of chronic obstructive pulmonary disease. Neurogastroenterol Motil 2011; 2: 201-203.

\section{Shareable abstract (@ERSpublications)}

Swallowing dysfunction is common in COPD patients with severe exacerbations but this kind of dysfunction is potentially correctable, at least in some patients. Further interventional studies on this topic are urgently needed. https://bit.ly/3mFKNq1

Cite this article as: Gonzalez Lindh M, Janson C, Koyi H. Swallowing dysfunction in patients hospitalised due to a COPD exacerbation. ERJ Open Res 2021; 7: 00515-2021 [DOI: 10.1183/ 23120541.00515-2021].
} 
3 Terada K, Muro S, Ohara T, et al. Abnormal swallowing reflex and COPD exacerbations. Chest 2010; 137: 326-332.

4 Steidl E, Ribeiro CS, Gonćalves BF, et al. Relationship between dysphagia and exacerbations in chronic obstructive pulmonary disease: a literature review. Int Arch Otorhinolaryngol 2015; 19: 74-79.

5 Terzi N, Normand H, Dumanowski E, et al. Noninvasive ventilation and breathing-swallowing interplay in chronic obstructive pulmonary disease. Crit Care Med 2014; 42, 565-573.

6 Gonzalez Lindh M, Janson C, Blom Johansson M, et al. Swallowing dysfunction in patients hospitalised due to a COPD exacerbation. ERJ Open Res 2021; 7: 00173-2021. 